\title{
Consumer Satisfaction And Stock Price Behavior: A Case Of Diminishing Returns
}

Samuel Keene, Colorado College, USA

Judith A. Laux, Colorado College, USA

\begin{abstract}
This study investigates stock price behavior of firms with differing levels of customer satisfaction as measured by American Customer Satisfaction Index (ACSI) scores. Using a fixed effects regression approach, it looks at the association between stock price changes and ACSI scores, total assets, total liabilities, and total revenues for six tyfour firms over a three-year period and discovers a marked difference between stock price changes for high-and low-scoring companies, indicating possible decreasing marginal returnsfor investments in customer satisfaction.
\end{abstract}

Keywords: Customer Satisfaction; ACSI; Diminishing Marginal Returns

\section{INTRODUCTION}

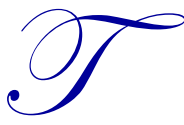

his study examines the association between customer satisfaction and stock appreciation. Based on current theoretical concepts and past research, we hypothesize that if customer satisfaction improves, it will have a greater impact on stock appreciation of companies with lower customer satisfaction than companies with already high customer satisfaction, testing both diminishing marginal returns and consumer utility theory. We first explain the theoretical concepts behind the research, then examine past literature on the subject of customer satisfaction and firm performance, describe how the experiment was conducted, interpret the results of the study, review possible limitations, and finally offer avenues for further research.

\section{THEORY}

Current studies suggest an increasingly important link between marketing and finance activity. In theory, customer service should affect a company's future performance; in a competitive market a company is unlikely to retain a dissatisfied customer. Utility theory holds that customers make consumption choices to maximize their happiness, a critical component of which is satisfactory customer service. Unless a monopoly exists, customers, given their price constraint, will give their business to companies that can provide the best service. The resulting cash flows from customer retention and attraction make high levels of customer service an extremely valuable asset, albeit one that does not appear as a specific line item on the balance sheet. Additionally, for some companies, customer service provides a means by which to differentiate themselves from the competition, becoming a core competency that is not easily replicated.

If high levels of service do indeed provide some sort of value to consumers, then the consumer's price elasticity will decrease (Anderson, 1996), carrying significant implications for customer loyalty; customers are likelier to return for future business given small fluctuations in price, allowing firms to charge slightly more for the product, resulting in an increase the firm's profitability. The value of customer service, therefore, can be defended theoretically. If future performance is affected, then the stock prices should respond in some way to customer satisfaction results (Fornell et al., 2006). In the following section, we present pertinent literature addressing the relationship between customer service and firm performance.

\section{LITERATURE REVIEW}

Customer satisfaction has become even more relevant over the past few years with the emergence of social media and expansion of online shopping. Since the consumer cannot touch or try out the product, other customers' 
opinions carry more weight. A 2013 study shows that an astounding $90 \%$ of customers are influenced by online reviews when making a buying decision (Gesenheus, 2013). A bad online purchasing experience does not just affect the likelihood of that individual's going back; comments and reviews are largely public, so it affects the decision of other possible customers. The ability to measure customer satisfaction and its effects is therefore a valuable endeavor.

Often, satisfying the customers leads to better future performance, as indicated by Ittner and Larcker (1998), who suggest that future revenue and retention are higher for satisfied customers than for dissatisfied customers. Financial analysts have recognized the importance of considering service when buying stocks. Interviews with 63 analysts from 40 brokerage firms found that analysts pay attention to intangibles such as customer satisfaction because "such assessment can lead to more reliable valuations of the firm," and ignoring satisfaction ratings can lead to insufficient or incorrect information (Luo and Homburg, 2008; Luo et al., 2013; Whitwell et al., 2007).

The primary debate on customer satisfaction focuses on how to measure accurately a variable that is largely subjective in nature. The American Customer Satisfaction Index (ACSI) was created with the goal of quantifying customer experiences. Started in 1994, the ACSI measures consumer satisfaction for a broad range of companies and surveys about 80,000 customers annually. A unique database, the ACSI constitutes the first national measure of quality from the customer's perspective. In Fornell et al. (1996), the fit of the model in explaining customer satisfaction across seven sectors demonstrates high R-squared values, with the lowest at .70 , indicating that the model is a good fit for describing customer satisfaction. High scores should, in theory, retain customers, lower the costs of attracting new customers, and reduce price elasticity of the customers (Anderson, 1996). Since it is the first comprehensive customer satisfaction database and the model is reasonably accurate, several studies have used the ASCI since its inception in 1994.

O'Sullivan and McCallig (2009) examine the relationship between customer satisfaction and both earnings and firm value; in particular they focus on the stock market reaction to customer satisfaction scores. Changes in customer satisfaction, as measured by the ACSI, are used as a proxy for the information not contained in accounting numbers. The authors generate results similar to previous studies: Customer satisfaction increases typically increase future earnings, firm value, and share prices. Fornell et al. (2006) demonstrate similar results. They find that, while the release of customer satisfaction information does not produce abnormal returns in an event study setting, it is possible to beat the market in the long run using customer satisfaction changes.

The above studies consistently find that higher customer satisfaction leads to improved future financial performance and stock performance. Importantly, the ACSI has proven to be a fairly reliable measure of customer satisfaction. The current study attempts to build on the existing literature by examining how stock prices vary between companies with low and high customer satisfaction scores. The data and methodology are described in the following section.

\section{Data and Methodology}

The purpose of this research is to investigate whether stock prices of companies with low customer satisfaction ratings are more sensitive to customer satisfaction levels than companies with high customer satisfaction ratings. The variables in the regression model include ACSI score, revenue, total assets, total liabilities, and end-of-year stock prices. Additionally, the data are collected from publicly traded companies in the ACSI and come from a variety of credible websites that disclose public financial information. Based on public information, a full data set for the variables (available upon request from the authors) is generated for the three-year period from 2011 to 2013.

The methodological approach, a regression model, is constructed as follows. First the natural $\log$ of each of the variables is calculated. The natural log is used to run the regression, including "if" statements for the top $25 \%$ and bottom $25 \%$ ACSI categories. While the null hypothesis is that no significant difference exists between high - and low-ACSI-scoring companies, in keeping with the law of diminishing marginal returns, we expect to reject this hypothesis and to find that the stock prices of companies with low customer satisfaction scores will have a higher correlation with customer satisfaction than the stock prices of companies with higher customer satisfaction scores. The regression equation is expressed as follows: 


$$
\operatorname{Ln}(\text { Stockprice })_{i}=\beta_{0}+\beta_{1} \ln (\mathrm{ACSI})_{\mathrm{i}}+\beta_{2} \ln (\mathrm{TA})_{\mathrm{i}}+\beta_{3} \ln (\mathrm{TL})_{\mathrm{i}}+\beta_{4} \ln (\text { Revenue })_{\mathrm{i}}+e_{\mathrm{i}}
$$

Where $\mathrm{i}=1 \ldots \mathrm{n}$, with $\mathrm{n}$ being the number of observations. The error term, $e$, is normally distributed with a mean equal to 0 .

\section{ACSI Information}

The ACSI data are taken from the website www.theacsi.org, which contains information on hundreds of companies in ten different economic sectors and 43 industries. For each of the companies scored, the ACSI conducts annual customer surveys and employs an econometric customer satisfaction equation to give each company a score between 0 and 100, with higher scores indicating greater satisfaction. Developed at the University of Michigan's Ross School of Business, the ACSI identifies drivers of customer satisfaction that are evaluated to generate this final score. A basic form of the equation is summarized in Figure 1.

Figure 1. ACSI Model

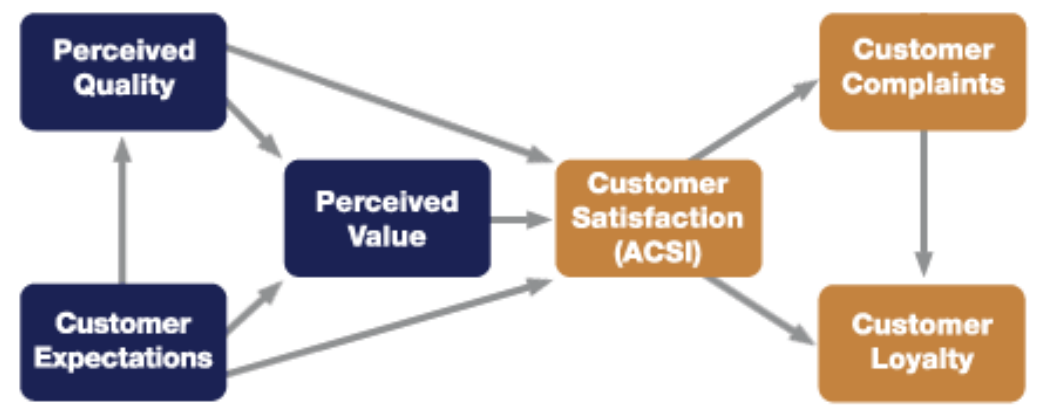

Source: www.theacsi.org/about-acsi/the-science-of-customer-satisfaction. On the left are the drivers of cust omer satisfaction and on the right are the out comes of cust omer satisfaction.

The ACSI publishes and publicly announces scores for each company. Yearly customer satisfaction scores are derived from the published ACSI industry reports as well as industry benchmark tables. The benchmark tables compare each company's score to the industry average since its date of inception in 1994. Studies have suggested that customer satisfaction, specifically from the ACSI, is associated with stock returns. As suggested in the 2006 Fornell et al. ACSI portfolio study, "firms that do better than their competitor in terms of satisfying customers (as measured by ACSI) generate superior returns." The question we address in the current study is whether those returns are more sensitive for companies with lower ACSI scores.

\section{Total Assets, Total Liabilities, and Revenue Data}

Studies show that customer satisfaction drives customer loyalty, which in turn leads to greater future revenues and profits. As a result revenue is included as a variable in this regression. Additionally, the Fornell et al. (2006) study regresses market value of equity as well as total assets and total liabilities against ACSI scores, finding that total as sets and liabilities are statistically significant, so those variables are also included in this study. The data for these three variables are taken from a few sources, primarily annual income statements and balance sheets from Yahoo Finance, Edger Online SEC filings, and occasionally from Bloomberg.com.

\section{Stock Prices}

The 2006 study shows that release of ACSI information does not affect stock prices in an event study context. However, as described earlier, companies with higher ACSI scores produce higher returns than expected in the long run, meaning a year or more. Accordingly, changes in stock prices are taken annually over a three-year period. Stock prices for the beginning and end of each company's fiscal year, as indicated by the annual 10-K report, are used (company list available upon request). The historical stock prices, adjusted for splits and dividends, are taken from Yahoo Finance and Edgar Online SEC Filings. 


\section{RESULTS AND ANALYSIS}

Two models are used. The first uses stock prices as the dependent variable and total assets, total liabilities, ACSI score, and revenue as independent variables in order to examine the effect of the independent variables on absolute stock prices, with a null hypothesis of no significant relationship between the dependent and independent variables. The second model addresses only companies in the top and bottom $25 \%$ of ACSI s cores in this sample, with scores 75 or below designating bottom and scores 83 or above designating top-scoring companies. This model tests our primary hypothesis that lower-scoring companies will achieve higher stock price changes (higher marginal returns).

The results for the general model $(n=191)$ demonstrate high significance, as shown in Table 1 below. The regression returns an $\mathrm{R}^{2}$ value of .4170 , meaning that $41.70 \%$ of the variation in the dependent variable can be explained by the independent variables. ${ }^{1}$ For customer service, $\ln$ ACSI returns a $\mathrm{p}$ value of .004; the null hypothesis is rejected at the .01 level and ACSI is significant. The coefficient on $\ln$ ACSI $\left(b_{1}\right)$ is 3.128 , indicating that, for every $1 \%$ increase in the ACSI, stock price should increase by about 3.128\%. This confirms that customer service is correlated with stock price movements and shows that financial measures are not the only factor influencing stock values.

Table 1. Fixed Effects Regression, All Variables, Full Sample

\begin{tabular}{|c|c|c|c|c|}
\hline \multicolumn{5}{|c|}{ Lnprice - original regression $\mathrm{R}^{2}=\mathbf{. 4 1 7 0}(\mathrm{n}=191)$} \\
\hline Variable & Coefficient & Robust std error & t value & P value \\
\hline $\ln \mathrm{ACSI}$ & 3.128 & 1.059 & 2.95 & .004 \\
\hline $\operatorname{lnTA}$ & 1.813 & .578 & 3.13 & .003 \\
\hline $\operatorname{lnTL}$ & -.493 & .435 & -1.13 & .262 \\
\hline lnRevenue & .741 & .615 & 1.21 & .232 \\
\hline constant & -45.545 & 8.077 & -5.64 & .000 \\
\hline
\end{tabular}

Total assets are significant, with a p value of .003 and a coefficient of 1.813 . Revenue is not significant, returning a $\mathrm{p}$ value of .232 and a coefficient of .741. Total liabilities are not significant either, with a $\mathrm{p}$ value of .262. Additionally, total liabilities has a negative coefficient (-.493), which would be expected because liabilities can cause the company to incur more risk, and typically riskier stocks have lower prices (Bachrach and Galai, 1979). In the second regression, the data are split up by ACSI scores and the model is regressed using top and bottom $25 \%$ ACSI scores, with 57 observations in the top category and 47 in the bottom category. The results appear in Tables 2 and 3 below.

Table 2. Fixed Effects Regression, Top 25\% ACSI Scores

\begin{tabular}{l|r|r|r|r}
\hline \multicolumn{2}{c}{ Lnprice - Top 25\% ACSI Scores $\mathrm{R}^{2}=.6931(\mathrm{n}=57)$} & t value & P value \\
\hline \multicolumn{1}{c|}{ Variable } & Coefficient & Robust std error & -.55 & .583 \\
\hline $\ln$ ACSI & $\mathbf{- . 7 8 9}$ & 1.423 & 3.20 & $\mathbf{. 0 0 3}$ \\
\hline $\ln$ A & 4.230 & 1.321 & -2.37 & .025 \\
\hline $\ln$ TL & -2.187 & .922 & .36 & .722 \\
\hline $\ln$ Revenue & .243 & .678 & -5.05 & .000 \\
\hline constant & -32.330 & 6.402 & & \\
\hline
\end{tabular}

\footnotetext{
${ }^{1} \mathrm{~A}$ modified Wald test gives a $\mathrm{p}$ value of .00 , indicating that the null hypothesis that the model is homoscedastic should be rejected. To correct for heteroscedasticity the regression is run again, this time using robust st andard errors. The model is a reasonably good fit and every variable is significant at the .05 level.
} 
Table 3. Fixed Effects Regression, Bottom 25\% ACSI Scores

\begin{tabular}{l|c|c|c|c}
\hline Lnprice - Bottom $25 \%$ & ACSI Scores $\mathrm{R}^{2}=.5450(\mathrm{n}=47)$ & t value & P value \\
\hline \multicolumn{1}{c|}{ Variable } & Coefficient & Robust std error & 2.71 & $\mathbf{0 1 5}$ \\
\hline $\ln$ ACSI & $\mathbf{5 . 3 9 0}$ & 1.986 & .72 & .483 \\
\hline $\ln$ A & .650 & .906 & .86 & .401 \\
\hline $\ln \mathrm{L}$ & .523 & .607 & 2.18 & $\mathbf{0 4 4}$ \\
\hline $\ln$ Revenue & .965 & .442 & -7.36 & .000 \\
\hline constant & -57.201 & 7.773 & & \\
\hline
\end{tabular}

In both cases the fit of the model is improved. The top scores return an R-squared value of .6931, and the regression using bottom scores yields an R-squared value of .5450. The R-squared values greatly improve; the model improves by segmenting it based on ACSI scores. However, by doing so the number of observations used in each regression decreases, from 191 to 57 and 47, respectively, which might constrict the conclusions we can draw about the results. Nonetheless some of the findings are interesting and should be noted.

In the top-performing ACSI category, only total assets and total liabilities are significant, and the lowest $\mathrm{p}$ value belongs to total assets, at .003. In the bottom-performing category, ACSI is significant at the .05 level, with a $\mathrm{p}$ value of .015, and revenue is significant at the .05 level as well. The significance of ACSI for bottom-performing companies but not for top-performing companies is not unexpected. The law of diminishing returns should apply to customer service as well as other economic variables; the marginal effects of increased customer service decrease as customer service ratings continue to increase. Improvements are more likely to have an effect on bottomperforming ACSI companies, because a $1 \%$ increase for low scores carries more weight than a $1 \%$ increase for the highest scores; moving from "dissatisfied" to "satisfied" is far more influential than moving from satisfied to more satisfied (Rust et al., 1995). ACSI score is insignificant for the top 25\% category and actually shows a negative relationship for this sample. For the full sample, and especially for the bottom $25 \%$ subsample, customer satisfaction is positively and significantly correlated with stock prices. This finding aligns well with our expectations about the returns to customer satisfaction for these firms.

\section{Limitations, Conclusions, and Avenues for Further Study}

Three potential limitations relate to this study. First and foremost, the data sample of publicly traded manufacturing companies from the ACSI is limited; expanding the sample size and including non-manufacturing companies could improve the results. A second limitation is that financial data are measured by each company's fiscal year, so the period covered by the ACSI may differ from fiscal years and cause errors. Finally, the three-year time period offers an abbreviated view, and replication during other, longer time periods might be warranted.

This study is designed to examine if stock prices of bottom-performing ACSI companies appreciate more than stock prices of top-performing ACSI companies. The results suggest that customer satisfaction is more significant for bottom-performing companies than top-performing companies, perhaps indicating a diminishing marginal returns scenario. Additionally, the results show that ACSI scores are significantly and positively correlated with stock prices, especially for companies with significantly lower ACSI scores. It would be interesting to research how far customer service can increase before diminishing returns set in or there is no longer a benefit to improved customer service. Is there an optimal level of customer satisfaction? Intuition might suggest the goal is always $100 \%$ satisfaction, but beyond a certain point the investments required to increase customer service and satisfaction may outweigh the benefits, an economic concept that access to ACSI information might help enforce.

\section{ACKNOWLEDGMENTS}

We would like to thank Mr. Jerry Bruni and the Bruni Foundation for supporting this research and enabling us to present it at the International Business Conference. Additional support for faculty involvement was provided by the Chapman Foundation. 


\section{AUTHOR BIOGRAPHIES}

Samuel Keene is a 2015 graduate of Colorado College, who majored in Economics. This work is based in its entirety on his senior thes is in economics.

Judy Laux is the Bill Barton Profess or of Economics and Business at Colorado College, teaching and researching in the areas of accounting and finance.

\section{REFERENCES}

Anderson, Eugene W. (1996). Customer Satisfaction and Price Tolerance. Marketing Letters, Vol. 7, No. 3: 265-74.

Bachrach, Benjamin and Galai, Dan. (1979). The Risk-Return Relationship and Stock Prices. The Journal of Financial and Quantitative Analysis, Vol. 14, No.2: pp.421-441.

Fornell, C., Johnson, M., Anderson, E., Cha, J. and Bry ant, B. (1996). The American Customer Satisfaction Index: Nature, Purpose and Findings. Journal of Marketing, Vol. 60: 7-18.

Fornell, Claes, Mithas, Sunil, Morgeson III, Forrest V., Krishan, M.S. (2006). Customer Satisfaction and Stock Prices: High Returns, Low Risk. Journal of Marketing, Vol. 70, No. 1: 3-14.

Gesenheus, Amy. (2013). Survey: 90\% Of Customers Say Buying Decisions Are Influenced By Online Reviews. Marketingland.com.

Ittner, Christian and Larcker, John. (1998). Are Nonfinancial Measures Leading Indicators of Financial Performance? An Analy sis of Customer Satisfaction. Journal of Accounting Research, Vol. 36, 1-35.

Luo, Xueming and Homburg, Christian. (2008). Satisfaction, Complaint, and the Stock Value Gap. American Marketing Association.

Luo, Xueming, Homburg, Christian, and Wieseke, Jan. (2013). Customer Satisfaction, Analy st Stock Recommendations, and Firm Value. Journal of Marketing Research, Vol. 47, No.6: 1041-1058.

O’Sullivan, Don and McCallig, John. (2009). Does Customer Satisfaction Influence the Relationship Between Earnings and Firm Value? Marketing Letters, Vol. 20, No. 4: 337-351

Rust, R.T., Zahorik, A.J. \& Keiningham, T.L. (1995). Return on Quality (ROQ): Making Service Quality Financially Accountable. Journal of Marketing, Vol. 59: 58-70.

Whitwell G, Lukas B, Hill P. (2007). Stock Analy sts' Assessments of the Shareholder Value of Intangible Assets. Journal of Business Research, Vol. 60, No. 1: 84-90. 